\title{
Effects of closed chain exercises for the lumbar region performed with local vibration applied to an unstable support surface on the thickness and length of the transverse abdominis
}

\author{
Kihyun Yun, $\mathrm{PT}^{1)}$, Sangyong Lee, PhD, $\mathrm{PT}^{2)}$, Jinsik Park, $\mathrm{PT}^{1)^{*}}$ \\ 1) Department of Physical Therapy, College of Rehabilitation Science, Daegu University: 12, 15 \\ Jillyang, Gyeongsan-si, Kyeongbuk 712-714, Republic of Korea \\ 2) Department of Physical Therapy, Youngdong University, Republic of Korea
}

\begin{abstract}
Purpose] This study examined the effects of closed chain exercises performed with local vibration applied to an unstable support surface on the thickness and length of the transverse abdominis. [Subjects] The subjects were 64 healthy university students who were randomly assigned to a bridge exercise with sling and vibration group (BESVG, $n=30$ ) and a bridge exercise with sling group (BESG, $n=34)$. [Methods] The bridge exercise was repeated four times per set and a total of 18 sets were performed: 9 sets in a supine position and 9 sets in a prone position. In both the BESVG and the BESG groups, the thickness and length of the transverse abdominis (TrA) were measured using ultrasonography with the abdomen "drawn-in" and the pressure of a biofeedback unit maintained at $40 \mathrm{mmHg}$, both before and after the intervention. [Results] In intra-group comparisons, the BESVG showed significant increases in the thickness of the TrA and significant decreases in the length of the TrA. The BESG showed significant increases in the thickness of the TrA. The BESVG showed significant increases in the thickness of the TrA and significant decreases in the length of the TrA compared to BESG. [Conclusion] Closed chain exercises for the lumbar region performed with local vibration applied to slings, which are unstable support surfaces, are an effective intervention for altering the thickness and length of the TrA.

Key words: Closed chain exercise, Vibration, Transverse abdominis
\end{abstract}

(This article was submitted Jun. 12, 2014, and was accepted Jul. 18, 2014)

\section{INTRODUCTION}

Ever since humans began to walk upright, some of their muscles have always been activated to maintain the balance of the body on narrow support surfaces. If these posturemaintaining muscles lose their function, low back pain will be induced due to the maintenance of unstable postures ${ }^{1)}$. Compared to healthy persons, patients with low back pain have reduced proprioceptive sense in the deep lumbar muscles, which makes the spine unstable, and this may lead to the recurrence of low back pain ${ }^{2}$. When healthy persons without any low back pain move their upper or lower limbs quickly, their transversus abdominis ( $\operatorname{TrA}$ ) muscles contract first to contribute to lumbar stabilization. However, in the case of patients with low back pain, the TrA muscles do not contract first ${ }^{3)}$. Delayed contraction of the TrA makes the trunk unstable, leading to reduced motor and postural control abilities and inefficient actions of the spinal mus-

*Corresponding author. Jinsik Park (E-mail: i99128@korea.

$\mathrm{kr})$

C2015 The Society of Physical Therapy Science. Published by IPEC Inc. This is an open-access article distributed under the terms of the Creative Commons Attribution Non-Commercial No Derivatives (by-ncnd) License $<$ http://creativecommons.org/licenses/by-nc-nd/3.0/> . cles $^{4}$. Richardson et al. ${ }^{5)}$ reported that the low back pain recurrence rate was reduced from 75 to $35 \%$ for three years after "abdominal drawing-in" exercises were performed to strengthen the TrA and multifidus muscles. Page ${ }^{6)}$ advised that rather than exercises using stable bearing surfaces, lumbar stabilization exercises using an unstable support surface are more effective for the maintenance of postural balance and the recovery of proprioceptive senses. Kang et al. ${ }^{7)}$ reported that according to the measurements taken using ultrasonography and the visual analogue scale after patients who had received herniated disc surgery had performed lumbar stabilization exercises using slings, which are unstable support surface, the activity of the TrA muscle increased and pain was relieved. Therefore, these previous studies indicate that closed chain exercises on an unstable support surface have the effect of activating lumbar stabilization muscles. The local vibration used for the intervention in this study took the form of isometric exercises that have been attracting great attention after results indicating that they positively affect motor function improvement and increase energy metabolism and blood flow rates ${ }^{8)}$. In addition, Rittweger et al. ${ }^{9)}$ reported that when vibration and exercises were performed by a group of low back pain patients, there was evidence of pain relief and improvement in their neuromuscular control ability.

This study compared and analyzed the changes in the 
thickness and length of the TrA muscle when vibration was applied to low back pain patients while they performed closed chain exercises on an unstable support surface.

\section{SUBJECTS AND METHODS}

The study subjects were 64 healthy university students residing in Daegu, Korea, who were randomly divided into a bridge exercise with sling and vibration group (BESVG) of 30 students, and a bridge exercise with sling group (BESVG) of 34 students. The BESVG's mean age was $21.8 \pm 1.6$ years, their mean height was $166.1 \pm 7.7 \mathrm{~cm}$, and their mean weight was $61.2 \pm 11.2 \mathrm{~kg}$. The BESG's mean age was $22.5 \pm 1.8$ years, their mean height was $169.6 \pm 7.2 \mathrm{~cm}$, and their mean weight was $60.7 \pm 9.4 \mathrm{~cm}$. Those who had neurologic or orthopedic problems or could not perform supine/prone bridge exercises due to pain or other problems were excluded from the study. All of the participants understood the purpose of this study and provided their written informed consent prior to their participation in this study, in accordance with the ethical principles of the Declaration of Helsinki.

When the subjects in the BESVG performed the bridge exercise in supine positions, each adopted a supine position on the table. For the starting posture, the subjects placed their two hands on the floor to support the body, maintained $90^{\circ}$ flexion postures of the hip and knee joints, and placed both ankles in a narrow sling. During the exercise, the subjects loaded their weight on both lower limbs, avoiding pelvic tilt and lifted their hip so that the trunk, pelvis, and lower limbs made a straight line. When the subjects in the BESVG performed the bridge exercise in the prone position, each adopted a prone position on the table. For the starting posture, the subjects placed their two ankles in a narrow sling while maintaining the shoulder and elbow joints at $90^{\circ}$. During the exercise, the subject loaded their weight on both lower limbs and elbows, avoiding pelvic tilt and lifted their hips so that the trunk, pelvis, and lower limbs made a straight line. The performance of each exercise four times constituted one set, and nine sets of the bridge exercise were performed in both the supine and prone positions. The subjects took a rest for 30 seconds after each set was completed. The BESG performed the same bridge exercises without local vibration in the supine and prone positions.

Local vibration was applied by suspending the two ropes of the sling that supported both lower limbs from vibration equipment (Redcord ${ }^{\circledR}$ Stimula, Norway), so that vibration was applied only while the subjects were performing bridge exercises and not during rest times. Vibration was applied at $15 \mathrm{~Hz}$ in the first 3 sets, at $20 \mathrm{~Hz}$ in the next 3 sets, and at $30 \mathrm{~Hz}$ in the last 3 sets.

An HD11XE ultrasound system (Philips, Netherlands) was used for ultrasonic imaging, and measurements were conducted by one person who was skilled in ultrasonic measurement. Before the ultrasonic measurements were taken, subjects lay comfortably in the supine position. A pressure biofeedback unit (PBU) was placed between the umbilicus and the floor, and a triangular pillow was placed under the subject's knees for support, thereby relaxing the
Table 1. Intergroup comparison of TrA thickness and length

\begin{tabular}{llcc}
\hline TrA & Group & Pre & Post \\
\hline Thickness (cm) & BESVG** & $0.3 \pm 0.1$ & $0.5 \pm 0.1^{\dagger}$ \\
& BESG** $^{*}$ & $0.3 \pm 0.1$ & $0.4 \pm 0.1$ \\
Length (cm) & BESVG* & $0.9 \pm 0.2$ & $0.8 \pm 0.2^{\dagger}$ \\
& BESG & $1.0 \pm 0.2$ & $0.9 \pm 0.3$ \\
\hline
\end{tabular}

BESVG: bridge exercise with sling and vibration group, BESG: bridge exercise with sling group, *: paired t-test, ${ }^{\dagger}$ : independent sample t-test, ${ }^{\dagger} ; *$ : $<0.05, * *: p<0.01$

subject's lower limbs. An assistant adjusted the pressure of the PBU to $40 \mathrm{mmHg}$, and the tester then placed the probe transversely on the top of the iliac crest and moved it to the center of the abdomen to align the end point of the TrA muscle with the end point of the screen. Once this had been done, the subject "drew in" the abdomen within the range in which the gradation of the PBU did not change, and the distance moved by the end point of the TrA muscle was measured. In this way, the distance was measured three times, both before and after the intervention and the average values were recorded. Since the total length of the TrA muscle could not be measured due to the nature of ultrasonography, the sliding distance from the abdomen to the outside was measured instead.

For the statistical analyses, intra-group changes in TrA thicknesses and lengths were analyzed using the paired ttest, and intergroup comparisons were performed using the independent sample t-test. Statistical processing was conducted using SPSS 12.0KO (SPSS, Chicago, IL, USA) with a significance level of $\alpha=0.05$.

\section{RESULTS}

According to the results of this study, in the intragroup comparison, the BESVG showed a significant increase in TrA thickness and a significant decrease in TrA length $(p<0.05)$. The BESG showed a significant increase in $\operatorname{Tr} A$ thickness $(p<0.05)$. In the intergroup comparison, the BESVG showed a significant increase in TrA thickness and a significant decrease in TrA length compared to the BESG $(\mathrm{p}<0.05)$ (Table 1).

\section{DISCUSSION}

Bridge exercises for lumbar stabilization use the performer's weight, increase joint alignment and stability, and improve proprioceptive stimuli and dynamic stabilization $^{10)}$. In a study involving 51 patients with chronic low back pain, Saliba et al. ${ }^{11)}$ demonstrated that bridge exercises on an unstable support surface provided by slings were more effective at increasing TrA muscle activity than bridge exercises on stable bearing surfaces as measured by ultrasonography. Eom et al. ${ }^{12)}$ reported that bridging exercises performed by healthy persons using slings as an unstable support surface showed larger increases in TrA thicknesses than bridging exercises performed by the same persons on stable bearing surfaces. In a study conducted by Brumagne et al. ${ }^{13)}$ with chronic low back pain patients, in which pro- 
prioceptive sense exercises and local vibrations were additionally applied, proprioceptive stimuli and deep muscle control abilities of the subjects improved. The studies cited above indicate that closed chain exercises on an unstable support surface are effective lumbar stabilization exercises for activating the TrA muscle. Hides et al. ${ }^{14)}$ reported that according to MRI and ultrasonography conducted after athletes had performed drawing-in exercises, the TrA muscle became thicker and shorter. Hides et al. ${ }^{15)}$ reported that weight-bearing stabilization exercises performed by low back pain patients greatly increased the thickness of the internal oblique muscles, and shortened the TrA muscle.

According to the results of this study, in the intragroup comparisons the BESVG showed a significant increase in TrA thickness and a significant decrease in TrA lengths; and the BESG showed a significant increase in TrA thicknesses. In the intergroup comparison, the BESVG showed a significant increase in TrA thickness and a significant decrease in TrA lengths compared to the BESG. Given these results, we consider the local vibration applied to the BESVG during closed chain exercises on an unstable support surface improved TrA muscle strength and power and lumber/pelvic tilt repositioning senses, thereby affecting TrA thickness and length more than in the BESG. Fontana et al. ${ }^{16)}$ reported that when healthy persons performed weightbearing exercise while vibration was applied, the subjects' lumber/pelvic tilt repositioning senses were improved by as much as $39 \%$. Therefore, applying local vibration during bridge exercises using slings in clinics should be an effective method for lumbar stabilization, because it improves TrA muscle activation. In addition, it can be presented to patients with chronic low back pain as an exercise intervention method in clinics.

Although many previous studies have measured TrA muscle activity through the thickness of the muscle using ultrasonic imaging, those that used local vibrations are few in number. Therefore, it is important that related studies in this field are undertaken in the future.

\section{REFERENCES}

1) Al-Obaidi SM, Al-Zoabi B, Al-Shuwaie N, et al.: The influence of pain and pain-related fear and disability beliefs on walking velocity in chronic low back pain. Int J Rehabil Res, 2003, 26: 101-108. [Medline] [CrossRef]

2) O'Sullivan PB, Burnett A, Floyd AN, et al.: Lumbar repositioning deficit in a specific low back pain population. Spine, 2003, 28: 1074-1079. [Medline] [CrossRef]

3) Hodges PW, Richardson CA: Contraction of the abdominal muscles associated with movement of the lower limb. Phys Ther, 1997, 77: 132-142, discussion 142-144. [Medline]

4) Hodges PW, Richardson CA: Inefficient muscular stabilization of the lumbar spine associated with low back pain. A motor control evaluation of transversus abdominis. Spine, 1996, 21: 2640-2650. [Medline] [CrossRef]

5) Richardson CA, Snijders CJ, Hides JA, et al.: The relation between the transversus abdominis muscles, sacroiliac joint mechanics, and low back pain. Spine, 2002, 27: 399-405. [Medline] [CrossRef]

6) Page P: Sensorimotor training: a "global" approach for balance training. J Bodyw Mov Ther, 2006, 10: 77-84. [CrossRef]

7) Kang HJ, An KO, Oak JS: Effect of sling exercise and segmental stabilizing exercise on the pain and activation of the deep muscle after lumbar disectomy. Off J Korean Assoc Exerc Professionals, 2013, 15: 117-128.

8) Jordan MJ, Norris SR, Smith DJ, et al.: Vibration training: an overview of the area, training consequences, and future considerations. J Strength Cond Res, 2005, 19: 459-466. [Medline]

9) Rittweger J: Vibration as an exercise modality: how it may work, and what its potential might be. Eur J Appl Physiol, 2010, 108: 877-904. [Medline] [CrossRef]

10) Lephart SM, Henry TJ: The physiological basis for open and closed kinetic chain rehabilitation for the upper extremity. J Sport Rehabil, 1996, 5: 71-87.

11) Saliba SA, Croy T, Guthrie R, et al.: Differences in transverse abdominis activation with stable and unstable bridging exercises in individuals with low back pain. N Am J Sports Phys Ther, 2010, 5: 63-73. [Medline]

12) Eom MY, Chung SH, Ko TS: Effects of bridging exercise on different support surfaces on the transverse abdominis. J Phys Ther Sci, 2013, 25: 1343-1346. [Medline] [CrossRef]

13) Brumagne S, Cordo P, Lysens R, et al.: The role of paraspinal muscle spindles in lumbosacral position sense in individuals with and without low back pain. Spine, 2000, 25: 989-994. [Medline] [CrossRef]

14) Hides J, Wilson S, Stanton W, et al.: An MRI investigation into the function of the transversus abdominis muscle during "drawing-in" of the abdominal wall. Spine, 2006, 31: E175-E178. [Medline] [CrossRef]

15) Hides JA, Belavý DL, Cassar L, et al.: Altered response of the anterolateral abdominal muscles to simulated weight-bearing in subjects with low back pain. Eur Spine J, 2009, 18: 410-418. [Medline] [CrossRef]

16) Fontana TL, Richardson CA, Stanton WR: The effect of weight-bearing exercise with low frequency, whole body vibration on lumbosacral proprioception: a pilot study on normal subjects. Aust J Physiother, 2005, 51: 259-263. [Medline] [CrossRef] 